\title{
Arterial hypoxaemia in cirrhosis: fact or fiction?
}

\author{
S Møller, J Hillingsø, E Christensen, J H Henriksen
}

\begin{abstract}
Background-Although low arterial oxygen tension $\left(\mathrm{Po}_{2}\right)$ has been claimed to occur in one to two thirds of patients with cirrhosis, hypoxaemia appears to be rare in clinical practice.

Aims-To assess the frequency of arterial hypoxaemia in cirrhosis in relation to clinical and haemodynamic characteristics.

Patients-One hundred and forty two patients with cirrhosis without significant hepatic encephalopathy (grades 0-I) (41 patients in Child class $A, 57$ in class $B$, and 44 in class $C$ ) and 21 patients with hepatic encephalopathy.

Results-Mean $\mathrm{Po}_{2}$ in $\mathrm{kPa}$ was 11.3 in Child class $A, 10.8$ in class $B, 10.6$ in class $C$, and 10.6 in patients with encephalopathy $(p<0.05)$. The fraction of patients with $\mathrm{Po}_{2}$ below the lower normal limit of 9.6 kPa was $10 \%, 28 \%, 25 \%$, and $43 \%$, respectively in class $A, B, C$, and in patients with encephalopathy $(p<0.05)$. Oxygen saturation $\left(\mathrm{So}_{2}\right)$ in these groups was respectively: $96 \%, 96 \%, 96 \%$, and $93 \%$ (NS). $\mathrm{So}_{2}$ was below the lower limit of $92 \%$ in $0 \%$, $9 \%, 7 \%$, and $24 \%(p<0.05)$. In patients without hepatic encephalopathy, a multivariate regression analysis revealed that independent determinants of a low $\mathrm{Po}_{2}$ were a high arterial carbon dioxide tension, a low systemic vascular resistance, and a low indocyanine green clearance $(\mathrm{p}<0.0001)$.
\end{abstract}

Conclusion-The prevalence of arterial hypoxaemia in cirrhosis is about $22 \%$ in patients without encephalopathy, but it varies from $10-40 \%$ depending on the degree of hepatic dysfunction. Arterial hypoxaemia in patients with cirrhosis of differing severity seems lower than previously reported, and patients with severe arterial hypoxaemia are rare.

(Gut 1998;42:868-874)

Keywords: cirrhosis; encephalopathy; haemodynamics; hepatopulmonary syndrome; hyperdynamic circulation; hypoxaemia

Gastroenterolog

Hvidovre Hospital

J Hillingsø

Department of Gastroenterology, Bispebjerg Hospital E Christensen

Correspondence to: Dr S Møller, Department of Clinical Physiology 54P1 Herlev Hospital, DK-2730 Herlev, Denmark.

Accepted for publication 18 December 1997

Arterial hypoxaemia has been recognised for more than a century in patients with chronic liver disease. ${ }^{1-5}$ It may be partly caused by concomitant chronic obstructive lung disease or cardiac dysfunction, ${ }^{6-8}$ but the liver disease per se and its complications may also influence oxygenation. In addition, low arterial oxygen tension in cirrhotic patients can originate from intrapulmonary shunting and ventilationperfusion (VA/Q) mismatch. ${ }^{6}$ Thus the clinical triad of liver disease, increased alveolar- arterial oxygen gradient, and evidence of pulmonary vascular dilatations has been defined as the hepatopulmonary syndrome. ${ }^{6}$ 10-12 Moreover, besides abnormalities in the splanchnic circulation as a result of portal hypertension, patients with cirrhosis may exhibit changes in systemic haemodynamics, such as a hyperdynamic circulation with increased cardiac output (CO) and heart rate, and reduced systemic vascular resistance (SVR), low arterial blood pressure, decreased central and arterial blood volume (CBV), and a short central circulation time (CCT), ${ }^{13-15}$ which may contribute to abnormal gas exchange.

Decreased oxygen tension has been claimed to occur in one to two thirds of patients with cirrhosis. $^{1-35} 16$ However, in clinical practice arterial hypoxaemia appears to be less common and the aim of the present study was therefore to assess the frequency of arterial hypoxaemia in relation to clinical and cardiovascular characteristics in a large population of patients with cirrhosis.

\section{Patients and methods}

STUDY POPULATION

The study population consisted of 163 consecutive patients with biopsy verified cirrhosis; 149 patients had a history of alcohol abusethat is, a consumption exceeding $50 \mathrm{~g}$ per day for more than five years. They had abstained from alcohol for at least one week before the study and had no signs of withdrawal symptoms at the time of the study. Fourteen patients had non-alcoholic cirrhosis, classified as either posthepatitic or cryptogenic. One hundred and forty two patients had hepatic encephalopathy of grade I or less and 21 patients had severe encephalopathy ranging from grades II to IV. ${ }^{17}$ None of the patients had experienced recent gastrointestinal bleeding. Table 1 summarises the clinical and biochemical characteristics of the patients and controls.

Patients participated after giving informed consent according to the Helsinki II declaration, and the study was approved by the local Ethics Committee for Medical Research in Copenhagen (Jr.No: V.100.2085/91). No complications or side effects were encountered during the study.
CATHETERISATION

All patients without hepatic encephalopathy underwent a haemodynamic investigation in order to diagnose portal venous hypertension and to assess the degree of severity. Catheterisation was performed in the morning after an overnight fast and at least one hour resting supine, according to a technique described elsewhere. ${ }^{18}$ A Cournand or Swan-Ganz catheter, size $7 \mathrm{~F}$, was guided under local 
Table 1 Clinical and biochemical characteristics of 163 cirrhotic patients with and without hepatic encephalopathy

\begin{tabular}{lll}
\hline Variable & $\begin{array}{l}\text { Patients without encephalopathyt } \\
(n=142)\end{array}$ & $\begin{array}{l}\text { Patients with encephalopathy } \\
(n=21)\end{array}$ \\
\hline $\begin{array}{l}\text { Patient characteristics } \\
\text { Age }(\mathrm{y})\end{array}$ & $55(26-71)$ & $57(37-71)$ \\
Body height $(\mathrm{cm})$ & $171(153-190)$ & $169(148-184)$ \\
Body weight $(\mathrm{kg})$ & $73(45-115)$ & $71(40-90)$ \\
Child class $(\mathrm{A}, \mathrm{B}, \mathrm{C})$ & $41,57,44$ & $0,2,19$ \\
Blood biochemistry/ & & $11.9(7.7-16.3)$ \\
Blood haemoglobin $(\mathrm{g} / \mathrm{dl})(13.0-17.6)$ & $11.6(7.1-15.8)$ & $134(26-750)$ \\
Serum AST $(\mathrm{U} / \mathrm{l})(10-40)$ & $64(19-357)$ & $144(19-452)^{\star \star}$ \\
Serum bilirubin $(\mu \mathrm{mol} / \mathrm{l})(2-17)$ & $32(5-214)$ & $400(68-999)$ \\
Serum alkaline phosphatase $(\mathrm{U} / \mathrm{l})(50-275)$ & $377(132-3585)$ & $0.39(0.19-0.66)^{\star \star}$ \\
Plasma coagulation factors 2,7, and 10 (units) $(0.70-1.30)$ & $0.63(0.23-1.30)$ & $26(20-33)^{\star \star}$ \\
Serum albumin $(\mathrm{g} / \mathrm{l})(37-55)$ & $33(18-48)$ & $136(42-449)$ \\
Serum creatinine $(\mu \mathrm{mol} / \mathrm{l})(49-121)$ & $96(45-1065)$ & $130(115-145)^{\star \star}$ \\
Serum sodium $(\mathrm{mmol} / \mathrm{l})(136-146)$ & $135(125-141)$ &
\end{tabular}

Results are expressed as mean (range).

†Grades 0 and I; †grades II-IV; Snormal values are given in parentheses.

${ }^{\star}{ }^{\star}$ Significance of differences between patients with and without hepatic encephalopathy $(p<0.01)$.

anaesthesia to the hepatic veins and right atrium via the femoral route under fluoroscopy. Pressures were measured by a capacitance transducer (Simonsen og Weel, Copenhagen, Denmark) in the wedged and free hepatic vein position in at least three different vessels, the midaxillary line being the zero pressure level. The hepatic venous pressure gradient (HVPG) was determined as the difference between the wedged and free hepatic pressures. Hepatic blood flow was determined by the indocyanine green (ICG) constant infusion technique. ${ }^{19}$ The ICG clearance was measured as the infusion rate divided by the arterial plasma concentration of ICG. ${ }^{19}$ A small indwelling polyethylene catheter was placed in the femoral artery with its tip at the aortic bifurcation by the Seldinger technique, and the arterial blood pressures were measured directly. The cardiac index was measured by the indicator dilution technique as described elsewhere ${ }^{20}$ and the heart rate was

Table 2 Haemodynamics of 142 cirrhotic patients without hepatic encephalopathy stratified according to the modified Child-Turcotte criteria

\begin{tabular}{|c|c|c|c|}
\hline Variable & Child class $A(n=41)$ & Child class $B(n=57)$ & Child class $C(n=44)$ \\
\hline \multicolumn{4}{|l|}{ Systemic haemodynamics $\neq$} \\
\hline $\begin{array}{l}\text { Mean arterical blood pressure (mm } \\
\mathrm{Hg})\end{array}$ & $94(69-122)$ & $87(68-120)^{\star}$ & $80(60-112) \dagger$ \\
\hline Heart rate (beats/min) & $73(54-108)$ & $79(54-104)^{\star}$ & $85(60-108) \dagger$ \\
\hline Cardiac index $\left(1 / \mathrm{min} / \mathrm{m}^{2}\right)$ & $3.3(2.1-5.1)$ & $3.7(2.1-5.7)$ & $4.3(1.9-6.5) \dagger$ \\
\hline $\begin{array}{l}\text { Central circulation time (seconds) } \\
(>14)\end{array}$ & $15.6(10.0-23.4)$ & $13.1(7.9-21.8)^{\star \star}$ & $11.2(7.3-21.1) \dagger$ \\
\hline $\begin{array}{l}\text { Central and arterial blood volume } \\
(\mathrm{ml} / \mathrm{kg} \text { ideal body weight })(>24)\end{array}$ & $23.7(16.0-37.6)$ & $22.8(16.1-34.7)$ & $21.1(13.8-31.2)^{\star}$ \\
\hline $\begin{array}{l}\text { Systemic vascular resistance } \\
\left(\mathrm{dyn} / \mathrm{s} / \mathrm{cm}^{5}\right)(>1600)\end{array}$ & $1323(578-2424)$ & $1102(565-2370)^{\star \star}$ & $864(431-1493) \dagger$ \\
\hline $\begin{array}{l}\text { Plasma volume }(1)(2.70-3.80) \\
\text { Splanchnic characteristics } \neq\end{array}$ & $3.63(1.80-6.16)$ & $3.91(2.00-6.27)$ & $3.98(2.39-5.70)$ \\
\hline $\begin{array}{l}\text { Hepatic venous pressure gradient }(\mathrm{mm} \\
\mathrm{Hg})(<5)\end{array}$ & $11.6(3.0-21.0)$ & $15.2(5.0-29.0)^{\star \star}$ & $17.6(5.0-28.0) \dagger$ \\
\hline $\begin{array}{l}\text { Postsinusoidal resistance }\left(\mathrm{dyn} / \mathrm{s} / \mathrm{cm}^{5}\right) \\
(<360)\end{array}$ & $943(236-3644)$ & $1164(330-4343)$ & $1448(232-4432)^{\star \star}$ \\
\hline Hepatic blood flow $(1 / \mathrm{min})(0.5-2.3)$ & $1.13(0.44-2.39)$ & $1.30(0.33-2.87)$ & $1.15(0.35-2.63)$ \\
\hline ICG clearance $(1 / \mathrm{min})(0.30-0.70)$ & $0.30(0.09-0.60)$ & $0.23(0.05-0.60)^{\star \star}$ & $0.16(0.01-0.68) \dagger$ \\
\hline $\begin{array}{l}\text { Galactose elimination capacity } \\
\quad(\mathrm{mmol} / \mathrm{min})(\mathrm{F}>14 ; M>17)\end{array}$ & $1.95(0.93-2.86)$ & $1.55(0.78-2.60)^{\star \star}$ & $1.28(0.01-2.14) \dagger$ \\
\hline
\end{tabular}

Results are expressed as mean (range).

Significance of differences between patient groups: ${ }^{\star} \mathrm{p}<0.05 v$ Child class $\mathrm{A} ;{ }^{\star \star} \mathrm{p}<0.01 v$ Child class A; $\nmid \mathrm{p}<0.005 v$ Child classes A and B.

$\ddagger$ Normal values are given in parentheses.

Table 3 Arterial gas tensions, alveolar-arterial oxygen gradient, arterial oxygen saturation, and pH in the 142 patients without and the 21 patients with hepatic encephalopathy

\begin{tabular}{|c|c|c|c|c|}
\hline & \multicolumn{3}{|c|}{ Patients without encephalopathy } & \multirow{2}{*}{$\begin{array}{l}\text { Patients with encepathopathy } \\
\text { Child classes } B \text { and } C(n=21)\end{array}$} \\
\hline & Child class $A(n=41)$ & Child class $B(n=57)$ & Child class $C(n=44)$ & \\
\hline $\begin{array}{l}\text { Arterial } \mathrm{O}_{2} \text { tension }\left(\mathrm{Po}_{2}\right) \\
\quad(\mathrm{kPa})(9.6-13.7) \ddagger\end{array}$ & $11.3(9.0-15.0)$ & $10.8(8.1-14.6)$ & $10.6(8.0-16.3)^{\star}$ & $10.6(5.5-15.7)^{\star}$ \\
\hline $\begin{array}{l}\text { Arterial } \mathrm{O}_{2} \text { saturation } \\
\quad\left(\mathrm{SO}_{2}\right)(\%)(92-99) \ddagger\end{array}$ & $96(92-100)$ & $96(90-100)$ & $96(91-100)$ & $93(68-98)$ \\
\hline $\begin{array}{l}\text { Alveolar-arterial } \mathrm{O}_{2} \\
\text { gradient }\left(\mathrm{AaPO}_{2}\right)(\mathrm{kPa})\end{array}$ & $2.6(0-4.9)$ & $3.4(0-5.8)^{\star}$ & $3.9(0-6.5)^{\star}$ & $4.5(0-10.5)^{\star}$ \\
\hline $\begin{array}{l}\text { Arterial } \mathrm{CO}_{2} \text { tension } \\
\quad\left(\mathrm{PCO}_{2}\right)(\mathrm{kPa}) \\
\quad(4.7-6.0) \ddagger\end{array}$ & $4.93(3.38-6.20)$ & $4.70(3.60-5.80)$ & $4.45(3.30-5.50)^{\star} \dagger$ & $4.46(2.40-8.80)^{\star}$ \\
\hline $\begin{array}{l}\text { Arterial pH (units) } \\
\quad(7.36-7.44) \ddagger\end{array}$ & $7.40(7.33-7.47)$ & $7.43(7.34-7.50)$ & $7.45(7.37-7.53)^{\star}+$ & $7.45(7.23-7.63)^{\star}$ \\
\hline
\end{tabular}

Results are expressed as mean (range).

Significance of differences between groups: ${ }^{\star} \mathrm{p}<0.05 v$ Child class $\mathrm{A} ; \mathrm{tp}<0.05 v$ Child class $\mathrm{B}$.

$\ddagger$ Normal values are given in parentheses. 

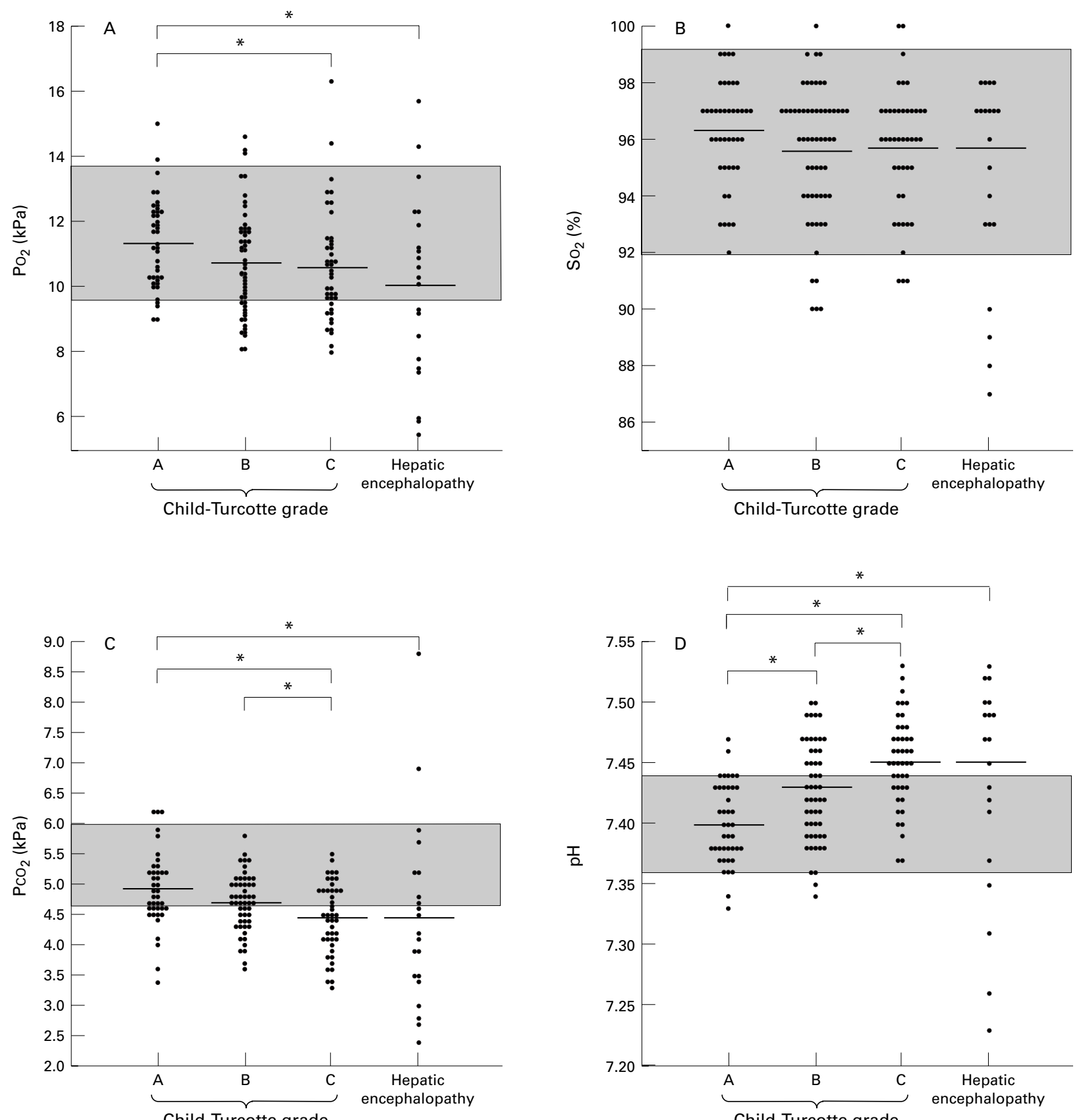

Figure 1 Distribution of $\mathrm{PO}_{2}(A), \mathrm{SO}_{2}(B), \mathrm{PCO}_{2}(C)$, and $p H(D)$ in 163 patients with cirrhosis stratified according to the modified Child-Turcotte criteria $(A, B$, or $C)$ without hepatic encephalopathy $(n=142)$ or with encephalopathy $(n=21)$. Bars indicate medians and the hatched area the reference interval.

determined by electrocardiography. The CBV (the blood volume in the cardiac cavities, lungs, and central arterial tree), was assessed as the CO multiplied by the CCT, as described elsewhere. ${ }^{1421}$ The CCT represents the mean indicator sojourn in the central vascular bed. ${ }^{14}$

MEASUREMENT OF BLOOD GASES

Arterial oxygen tension $\left(\mathrm{PO}_{2}\right)$, carbon dioxide tension $\left(\mathrm{PCO}_{2}\right)$, and $\mathrm{pH}$ were measured by an ABL-300 blood gas analyser and arterial oxygen saturation $\left(\mathrm{SO}_{2}\right)$ by an OSM-2 haemoxymeter (Radiometer, Copenhagen, Denmark). Coefficients of variation of $\mathrm{PO}_{2}, \mathrm{SO}_{2}$, and $\mathrm{PCO}_{2}$ were determined from duplicate arterial samples taken at an interval of less than
15 minutes and were respectively: $0.7 \%, 2.1 \%$, and $4.6 \%$. The alveolar-arterial oxygen gradient $\left(\mathrm{AaPO}_{2}\right)$ was calculated from the alveolar gas equation:

$\mathrm{AaPO}_{2}=\left(\mathrm{FIO}_{2}(\mathrm{~PB}-47)-\left(\mathrm{PACO}_{2} / \mathrm{R}\right)+\mathrm{FIO}_{2}\right.$ $\left.(1-\mathrm{R})\left(\mathrm{PACO}_{2} / \mathrm{R}\right)\right)-\mathrm{Po}_{2}$,

where $\mathrm{FIO}_{2}$ is the $\mathrm{O}_{2}$ inspiratory fraction, $\mathrm{PB}$ is the barometric pressure, and $\mathrm{PACO}_{2}$ is alveolar $\mathrm{PCO}_{2}$, assumed to be equal to $\mathrm{PCO}_{2} \cdot{ }^{16} \mathrm{R}$ is the respiratory exchange ratio set to be 0.80 as found in other studies of cirrhotic patients. ${ }^{16}$ The carbon monoxide diffusing capacity (transfer factor, TLCO) was measured by 
Table 4 Regression coefficients, standard errors, $p$ values, and adjusted $r^{2}$ for the multiple regression models of determinants of arterial gas tension, saturation, and pH in 142 cirrhotic patients

\begin{tabular}{|c|c|c|c|c|c|c|c|}
\hline & Variable & Scoring & $\begin{array}{l}\text { Regression } \\
\text { coefficient }\end{array}$ & $S E$ & $p$ Value & $\begin{array}{l}\text { Adjusted } r^{2} \text { for } \\
\text { model }\end{array}$ & $p$ Value for model \\
\hline \multirow[t]{4}{*}{$\mathrm{PO}_{2}$} & Constant & & 13.50 & & & 0.20 & $<0.0001$ \\
\hline & $\mathrm{PCO}_{2}$ & $\mathrm{kPa}$ & -0.92 & 0.22 & $<0.0001$ & & \\
\hline & ICG clearance & $\mathrm{ml} / \mathrm{min}$ & 3.18 & 1.02 & $<0.005$ & & \\
\hline & SVR & $\mathrm{dyn} / \mathrm{s} / \mathrm{cm}^{5}$ & 0.07 & 0.02 & $<0.005$ & & \\
\hline \multirow{2}{*}{$\mathrm{SO}_{2}$} & Constant & & 97.64 & & & 0.06 & $<0.005$ \\
\hline & Heart rate & per min & -0.02 & 0.01 & $<0.005$ & & \\
\hline \multirow[t]{3}{*}{$\mathrm{PCO}_{2}$} & Constant & & 7.50 & & & 0.29 & $<0.0001$ \\
\hline & $\mathrm{PO}_{2}$ & $\mathrm{kPa}$ & -0.20 & 0.03 & $<0.0001$ & & \\
\hline & Child class & Score & -0.09 & 0.02 & $<0.0001$ & & \\
\hline \multirow[t]{4}{*}{$\mathrm{pH}$} & Constant & & 7.59 & & & 0.46 & $<0.0001$ \\
\hline & $\mathrm{PO}_{2}$ & $\mathrm{kPa}$ & -0.011 & 0.002 & $<0.0001$ & & \\
\hline & Child class & Score & 0.006 & 0.001 & $<0.0001$ & & \\
\hline & $\mathrm{PCO}_{2}$ & $\mathrm{kPa}$ & -0.019 & 0.005 & $<0.0005$ & & \\
\hline
\end{tabular}

$\mathrm{PO}_{2}$, arterial $\mathrm{O}_{2}$ tension; $\mathrm{SO}_{2}$, arterial $\mathrm{O}_{2}$ saturation; $\mathrm{PCO}_{2}, \mathrm{CO}_{2}$ arterial tension; SVR, systemic vascular resistance; ICG, indocyanine green.

the single breath technique (Mijnhardt Diffusion Spirometer, Diffusimat 2000, Bruvik, The Netherlands) with a nitrogen mixture containing $0.3 \%$ carbon monoxide, $10 \%$ helium, and $20 \%$ oxygen. The results were adjusted for blood haemoglobin and compared with predicted reference values.

In patients with hepatic encephalopathy clinical and biochemical characteristics were obtained in addition to the measurements of gas tensions, $\mathrm{So}_{2}$, and $\mathrm{pH}$. The galactose elimination capacity (GEC) was measured as previously described. ${ }^{22}$ The serum concentrations of albumin, bilirubin, aspartate aminotransferase, alkaline phosphatase, coagulation factors 2,7 , and 10 , creatinine, sodium,
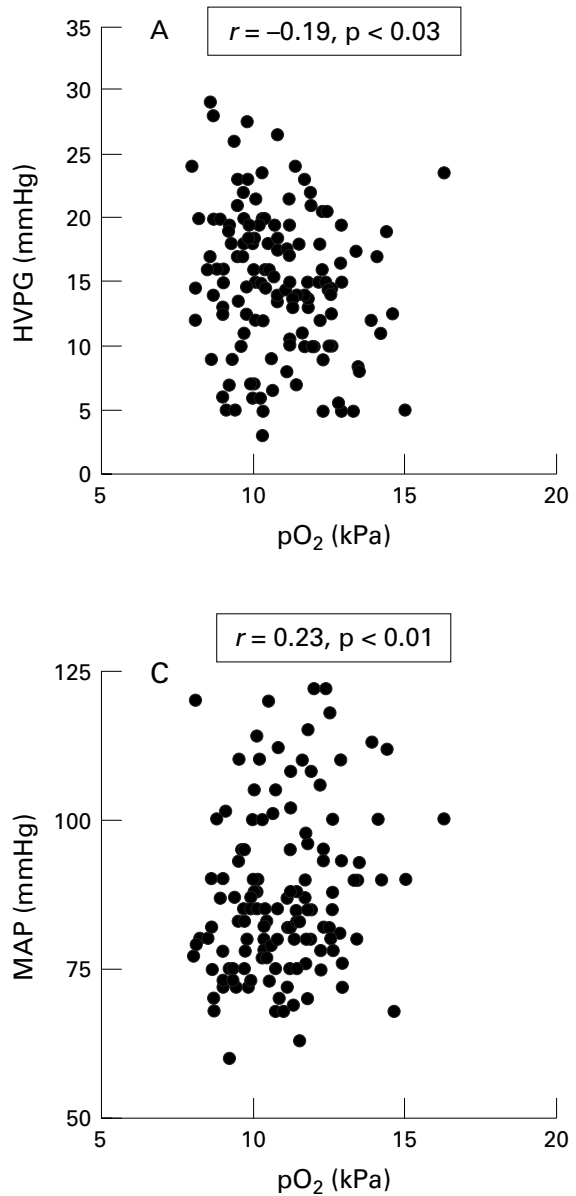

and potassium were measured by routine methods with an autoanalyser (SMAC, Technicon Instruments Corporation, Tarrytown, New York, USA).

STATISTICS

Data are expressed as mean and range. The Mann-Whitney or Kruskal-Wallis tests were used to compare differences between patient groups. The prevalences of arterial hypoxaemia are given with $95 \%$ confidence limits. Correlation analyses were performed with the Spearman correlation analysis test. To examine the association of arterial hypoxaemia with the severity of liver disease, we performed a multiple regression analysis by including pertinent
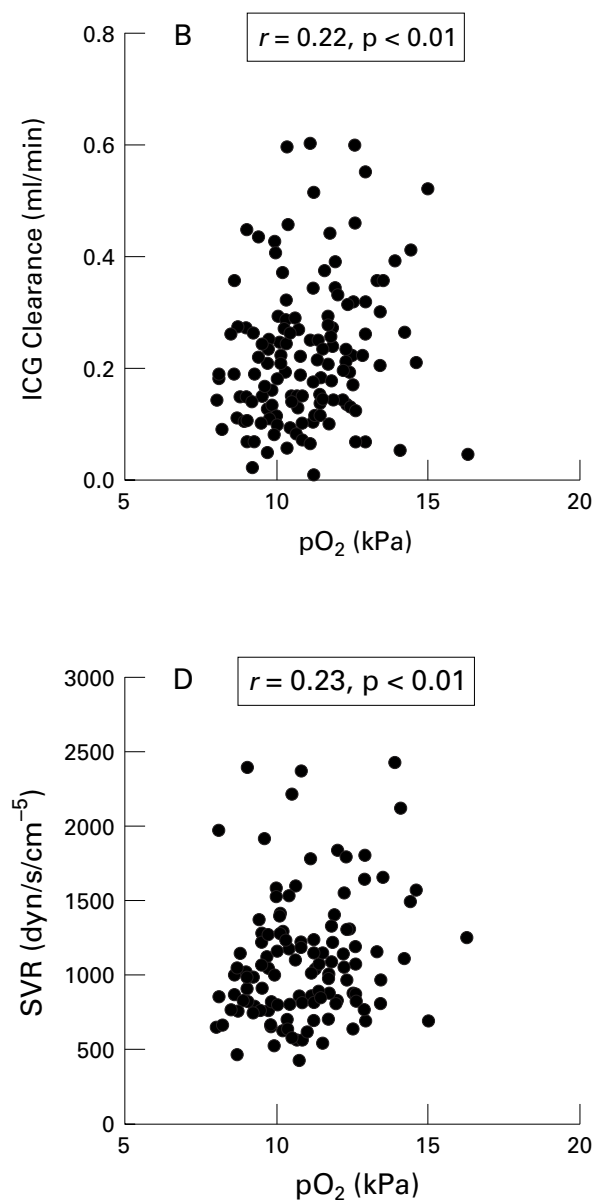

Figure 2 Correlation between $\mathrm{PO}_{2}$ and HVPG, ICG clearance, MAP, and SVR in 142 patients without encephalopathy. 

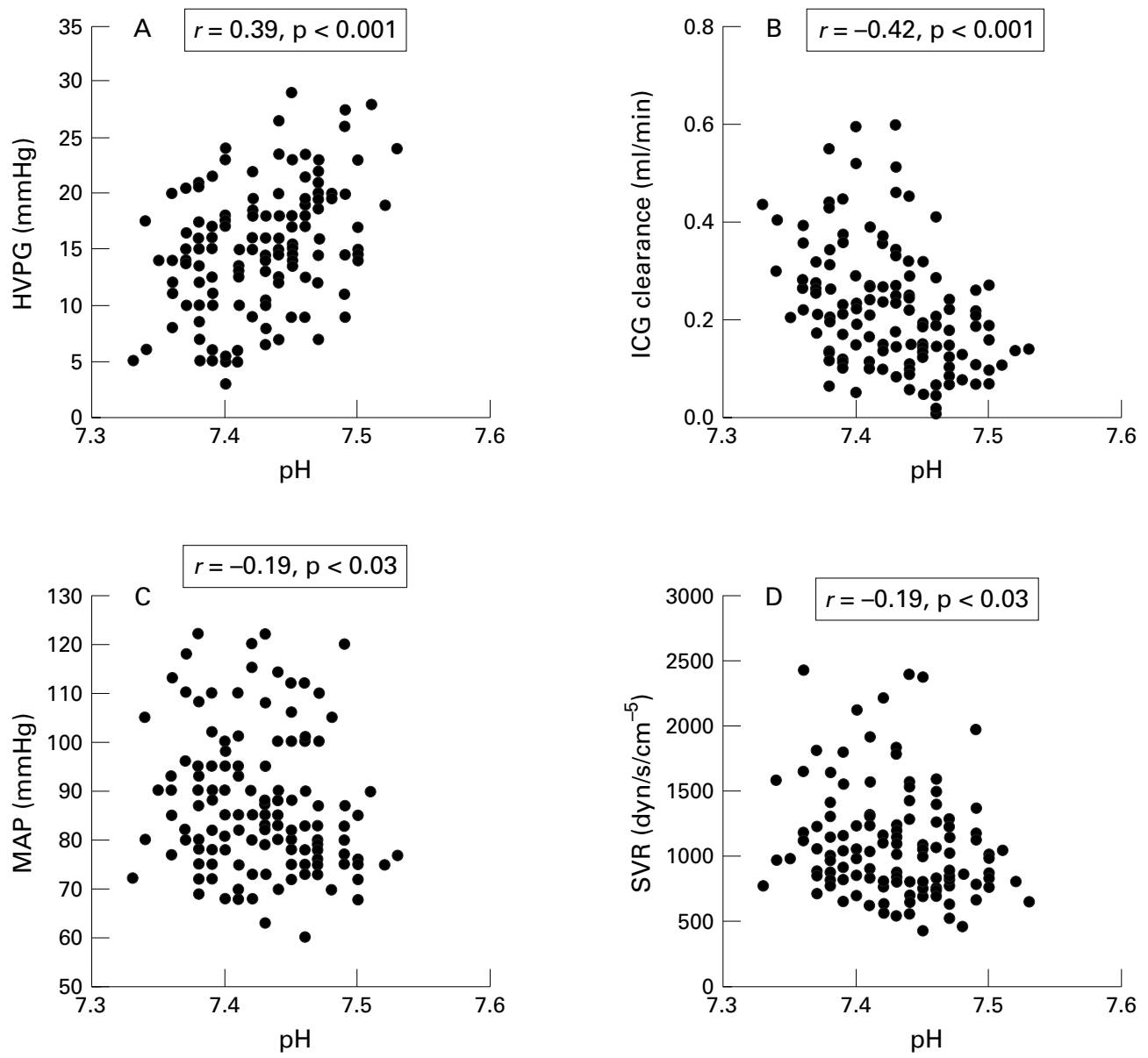

Figure 3 Correlation between $p H$ and HVPG, ICG clearance, MAP, and SVR in 142 patients without encephalopathy.

clinical and haemodynamic variables. After an initial bivariate analysis, insignificant variables were excluded by the backwards elimination technique. ${ }^{23}$ The two tailed significance level of the type 1 error was fixed at $5 \%$.

\section{Results}

Table 1 shows the characteristics of the 142 patients without encephalopathy and the 21 patients with encephalopathy and and table 2 shows the haemodynamic parameters of patients without encephalopathy. In general, patients in Child class $\mathrm{C}$ had a more disturbed systemic and splanchnic circulation than had patients in classes A and B. Thus patients in Child class $C$ had a higher degree of portal hypertension, as reflected by a higher HVPG, and a higher degree of hepatocellular damage, as reflected by a lower ICG clearance and GEC. Patients in Child class $\mathrm{C}$ also exhibited a higher degree of peripheral arterial vasodilatation, as reflected by a lower arterial blood pressure and a lower SVR (table 2).

Table 3 and figure 1 summarise the arterial gas tensions, oxygen saturation, and $\mathrm{pH}$ in the patient groups. $\mathrm{PO}_{2}$ and $\mathrm{SO}_{2}$ were significantly lower in patients with advanced disease and $\mathrm{Po}_{2}$ was lowest in the patients with encephalopathy. $\mathrm{AaPo}_{2}$ was higher in patients with encephalopathy and advanced cirrhosis than in those with less advanced disease in Child class $A(p<0.05)$ (table 3). The $\mathrm{PCO}_{2}$ was significantly lower and $\mathrm{pH}$ significantly higher in patients with ad- vanced disease and the $\mathrm{PCO}_{2}$ was lowest and $\mathrm{pH}$ highest in Child class $\mathrm{C}$ patients and in patients with encephalopathy. The fraction of patients in each group with an arterial oxygen tension below the lower normal limit of $9.6 \mathrm{kPa}$ was, respectively, $10 \%$ (95\% confidence limit 3 to 23 ), $28 \%$ (17 to 42 ), $25 \%$ (13 to 30 ), and $43 \%$ (22 to 66) in classes A, B, C, and in patients with encephalopathy $(p<0.05)$.

The prevalence of arterial hypoxaemia in patients with cirrhosis without encephalopathy was about $22 \%(15-30) . \mathrm{So}_{2}$ was below the lower normal limit of $92 \%$ in $0 \%(0-8), 9 \%$ (3-19), 7\% (1-19), and 23\% (8-47) ( $\mathrm{p}<0.05)$. None of the patients without encephalopathy had severe hypoxaemia with a $\mathrm{PO}_{2}$ below 8.0 $\mathrm{kPa}$ or an $\mathrm{So}_{2}$ below $85 \%$. Among patients with encephalopathy, 29\% (11-52) had severe hypoxaemia with $\mathrm{PO}_{2}$ below $8.0 \mathrm{kPa}$ and one patient had an $\mathrm{SO}_{2}$ below $85 \%$. In a subset of patients $(n=19)$, the diffusing capacity was measured and was reduced in all patients $(18.8$ (11.0-28.5) $\mathrm{ml} / \mathrm{min} / \mathrm{mm} \mathrm{Hg}$ versus predicted values of $28.5(22.0-38.5) \mathrm{ml} / \mathrm{min} / \mathrm{mm} \mathrm{Hg}$, $\mathrm{p}<0.0001)$. These data have previously been published in part together with conventional lung function tests. ${ }^{24}$ In these patients the diffusing capacity correlated significantly with the arterial oxygen saturation $(r=0.74$, $\mathrm{p}<0.005)$.

In patients without encephalopathy, the $\mathrm{PO}_{2}$ correlated directly with the ICG clearance $(r=0.22, \mathrm{p}<0.01)$, the mean arterial blood 
pressure (MAP; $r=0.23, \mathrm{p}<0.01$ ), and the SVR $(r=0.23, \mathrm{p}<0.01)$ and inversely with the HVPG $(r=-0.19, \mathrm{p}<0.03) \quad($ fig 2$)$. No significant relation of $\mathrm{PO}_{2}$ to blood haemoglobin or indicators of renal dysfunction such as serum creatinine was observed. In order to identify independent determinants of the arterial oxygen tension in cirrhosis, a multivariate regression analysis was performed. It showed that a low oxygen tension primarily was determined by a high $\mathrm{PCO}_{2}$, a low SVR, and a low ICG clearance (table 4). The oxygen saturation was primarily determined by the heart rate. $\mathrm{AaPO}_{2}$ correlated significantly with the heart rate $(r=0.28, \mathrm{p}<0.01)$, the cardiac index $(r=0.19, \mathrm{p}<0.05)$, SVR $(r=-0.33, \mathrm{p}<0.001)$, MAP $(r=0.30, \mathrm{p}<0.001)$, and the ICG clearance $(r=-0.31, \mathrm{p}<0.001) . \mathrm{AaPo}_{2}$ correlated directly with $\mathrm{pH}(r=0.57, \mathrm{p}<0.001)$ and negatively with $\mathrm{PO}_{2}(r=-0.90, \mathrm{p}<0.001)$.

The $\mathrm{PCO}_{2}$ correlated negatively with the heart rate $(r=-0.23, \mathrm{p}<0.005)$ and the HVPG $(r=-0.27, \mathrm{p}<0.005)$. The $\mathrm{pH}$ correlated directly with the heart rate $(r=0.23, \mathrm{p}<0.01)$, the HVPG $(r=0.39, \mathrm{p}<0.001)$, the postsinusoidal resistance $(r=0.23, \mathrm{p}<0.01)$, and the plasma volume $(r=0.21, \mathrm{p}<0.03)$ and negatively with the ICG clearance $(r=-0.42, \mathrm{p}<0.001)$, GEC $(r=-0.30, \mathrm{p}<0.005), \operatorname{MAP}(r=-0.19, \mathrm{p}<0.03)$, the SVR $(r=-0.19, \mathrm{p}<0.03)$, CCT $(r=-0.26$, $\mathrm{p}<0.01)$, and $\mathrm{Po}_{2}(r=-0.45, \mathrm{p}<0.001)$ (fig 3). Table 4 shows independent determinants of $\mathrm{PCO}_{2}$ and $\mathrm{pH}$ in the multivariate analyses.

\section{Discussion}

The main findings of the present study are that mild arterial hypoxaemia occurs in about $22 \%$ of patients with cirrhosis and severe hypoxaemia seems to occur primarily in patients with advanced disease and encephalopathy. There is a significant, although weak, correlation between the degree of arterial dysoxygenation on the one hand and the deranged systemic and portal haemodynamics on the other.

Arterial hypoxaemia in patients with cirrhosis of various aetiologies has been known for many years..$^{1-32526}$ However, the prevalence reported in the literature varies from about $30 \%$ to $70 \%$ in the different patient populations. ${ }^{13627}$ Thus, our observation of a prevalence of arterial hypoxaemia of $22 \%$ in a large consecutive population of patients with cirrhosis is somewhat lower than published values. A potential variation in the definition of hypoxaemia between different laboratories is an unlikely explanation for the discrepancy between our results and those of others. One explanation could be a difference in the severity of the disease in the patients studied. Our study population consisted of a broad spectrum of patients with cirrhosis, ranging from those with almost normal liver function to those with severe hepatic insufficiency. We found the lowest oxygen tensions and saturations in patients with severely impaired liver function and encephalopathy; hence the patients entered in other studies may have reached a more advanced state of the disease with many candidates for liver transplantation. ${ }^{35626}$ Previous studies have indicated that the aetiology, the degree of liver dysfunction, and the stage of the disease affect the degree of dysoxygenation. ${ }^{262829}$ In this sense, we found significant associations between the arterial oxygen tension and the ICG clearance and the HVPG, which reflect both the metabolic/excretory function and the derangement of the splanchnic circulation. A few of our patients with advanced cirrhosis had supranormal values of $\mathrm{PO}_{2}$ and $\mathrm{SO}_{2}$, but this is probably explained by hyperventilation, as the patients did not receive oxygen.

Arterial hypoxaemia in patients with advanced cirrhosis may be a consequence of either parenchymal lung disease, including interstitial lung diseases, obstructive airway disease, pleural effusions, or pulmonary vascular disease. ${ }^{27}$ In the absence of primary lung disease, the major causes of arterial hypoxaemia in cirrhosis and portal hypertension may be pulmonary arteriovenous shunting, portopulmonary shunting, and intrapulmonary vascular abnormalities, limited diffusion of oxygen, and/or ventilation-perfusion mismatching. ${ }^{3630} \mathrm{Im}$ paired regulation of the pulmonary vascular tone has been put forward as an important cause of the low ventilation:perfusion ratio in cirrhotic patients with a high CO and low SVR and low pulmonary vascular resistance and it is conceivable that an impaired hypoxic pulmonary vasoconstriction contributes to the ventilationperfusion mismatch in these patients. ${ }^{29}{ }^{30}$ Our findings of a relation between the arterial blood pressure and the SVR on the one hand and $\mathrm{PO}_{2}$ on the other agree with this concept. Fluid retention may cause interstitial and airway oedema, which may reduce alveolar ventilation in some areas. ${ }^{1231}$ Finally, in the presence of ascites the basal parts of the lungs may be compressed, leading to hypoventilation. ${ }^{32}$

The hepatopulmonary syndrome now constitutes a well defined clinical entity characterised by the clinical triad of chronic liver disease, increased alveolar-arterial oxygen gradient, and evidence of intrapulmonary vascular dilatations. ${ }^{11}$ Results of the present study confirm an increased alveolar-arterial oxygen gradient which seems to be associated with the severity of the liver disease and the systemic and splanchnic haemodynamics. The significant direct correlation between the diffusing capacity and the oxygen saturation as described in the present study lends further support to a diffusion defect. However, it is still a matter of debate whether the reduction in lung diffusion capacity and arterial hypoxaemia observed in chronic liver disease is caused primarily by vascular dilatation or by a ventilation-perfusion defect owing to the reasons given above. ${ }^{27} 30$

Low carbon dioxide tensions and respiratory alkalosis were found especially in patients with advanced disease. The pathogenesis remains unclear, ${ }^{33}$ but hypoxaemia per se has been suggested as a leading cause. ${ }^{33}$ Our findings of the highest arterial $\mathrm{pH}$ in patients with advanced disease and significant correlations of $\mathrm{pH}$ and indicators of liver failure, such as ICG clearance, the GEC, and splanchnic and systemic haemodynamics, favour this hypothesis. Our findings of a significant negative correlation 
between the $\mathrm{Po}_{2}$ and $\mathrm{pH}$ support arterial hypoxaemia as a contributing factor to the acid-base derangements in cirrhosis. However, other factors such as interstitial oedema, reduced lung compliance, abnormal respiratory mechanics, and sex hormone abnormalities in cirrhosis may also be implicated. ${ }^{34-36}$ In contrast, two of our patients with encephalopathy had increased $\mathrm{PCO}_{2}$ (fig $1 \mathrm{C}$ ). Both patients had a low $\mathrm{pH}$ and one patient a low $\mathrm{Po}_{2}$ which suggests the presence of hypoventilation and advanced cerebral dysfunction, as no history of primary lung disease was known.

In conclusion, the frequency of arterial hypoxaemia in a large consecutive population of patients with cirrhosis is about $22 \%$ and varies from 10 to $40 \%$ depending on the severity of the liver disease. This prevalence is lower than previously estimated, and patients with severe arterial hypoxaemia are rare.

The authors wish to express their gratitude to Hanne Hansen MSc, for her excellent assistance in handling the database. This study was supported by the John and Birthe Meyer Foundation and the Tode Foundation. Professor J H Henriksen is the 1997 winner of the Klein-Prize.

1 Rodman T, Sobel M, Close HP. Arterial oxygen unsaturation and ventilation-perfusion defect of Laënnec's cirrhosis. N Engl F Med 1960;263:73-7.

2 Furukawa T, Hara N, Yasumoto K, et al. Arterial hypoxemia in patients with hepatic cirrhosis. Am $\mathcal{F} M e d$ Sci 1984;287: $10-13$.

3 Eriksson LS. Hypoxemia in patients with liver cirrhosis. Acta Gastroenterol Belg 1990;53:209-15.

4 Andrivet P, Cadranel J, Housset B, et al. Mechanisms of impaired arterial oxygenation in patients with liver cirrhosis and severe respiratory insufficiency-effects of indomethacin. Chest 1993;103:500-7.

5 Rodriguez-Roisin R, Krowka MJ. Is severe arterial hypoxaemia due to hepatic disease an indication for liver transplantation? A new therapeutic approach. Eur Resp $\mathcal{F} 1994 ; 7$ $839-42$

6 Agusti AGN, Roca J, Bosch J, et al. The lung in patients with cirrhosis. F Hepatol 1990;10:251-7.

7 Rakela J, Krowka MJ. Cardiovascular and pulmonary complications of liver diseases. In: Zakim D, Boyer TD, eds. Hepatology. A textbook of liver disease. Philadelphia: Saunders, 1990:530-7.

$8 \mathrm{Ma} \mathrm{Z}$, Lee SS. Cirrhotic cardiomyopathy: getting to the heart of the matter. Hepatology 1996;24:451-9.

9 Söderman C, Juhlin-Dannfelt A, Lagerstrand L, et al. Ventilation-perfusion relationships and central haemodynamics in patients with cirrhosis. Effects of a somatostatin analogue. 尹 Hepatol 1994;21:52-7.

10 Rodriguez-Roisin R, Agusti A, Roca J. The hepatopulmonary syndrome- new name, old complexities. Thorax nary syndrome-

11 Krowka MJ, Cortese DA. Hepatopulmonary syndromecurrent concepts in diagnostic and therapeutic consideracurrent concepts in diagnostic
tions. Chest 1994;105:1528-37.

12 Lange PA, Stoller JK. The hepatopulmonary syndrome. Ann Intern Med 1995;122:521-9.

13 Henriksen JH. Systemic haemodynamic alterations in hepatic cirrhosis. Eur f Gastroenterol Hepatol 1991;3:70513.
14 Henriksen JH, Bendtsen F, Sørensen TIA, et al. Reduced central blood volume in cirrhosis. Gastroenterology 1989;97: 1506-13.

15 Groszmann RJ. Vasodilatation and hyperdynamic circulatory state in chronic liver disease. In: Bosch J, Groszmann RJ, eds. Portal hypertension. Pathophysiology and treatment. Oxford: Blackwell Science, 1994:17-26.

16 Rodriguez-Roisin R, Roca J, Agusti AG, et al. Gas exchange and pulmonary vascular reactivity in patients with liver cirrhosis. Am Rev Respir Dis 1987;135:1085-92.

17 Lotterer E. Portosystemic encephalopathy: diagnostic assessment. In: Holstege A, Schölmerich J, Hahn EG, eds. Portal hypertension. Dordrecht: Kluwer, 1995:347-55.

18 Henriksen JH, Ring-Larsen H, Kanstrup I-L, et al. Splanchnic and renal elimination and release of catecholamines in cirrhosis. Evidence of enhanced sympathetic nervous activity in patients with cirrhosis. Gut 1984;25:1034-43.

19 Henriksen JH, Winkler W. Hepatic blood flow determination. A comparison of 99-Tc-diethyl-IDA and indocyanine green as hepatic blood flow indicators in man. 7 Hepatol 1987;4:66-70

20 Henriksen JH, Ring-Larsen H, Christensen NJ. Circulating noradrenaline and central haemodynamics in patients with cirrhosis. Scand 7 Gastroenterol 1985;20:1185-90.

21 Møller S, Henriksen JH. Hemodynamics, distribution of blood volume, and kinetics of vasoactive substances in cirrhosis. In: Epstein $\mathrm{M}$, ed. The kidney in liver disease. rhosis. In: Epstein M, ed. The kidney in liver

22 Tygstrup N. Determination of the hepatic galactose elimination capacity after a single intravenous injection in man. Acta Physiol Scand 1963;58:162-72.

23 Armitage P, Berry G. Statistical methods in medical research. Oxford: Blackwell Science, 1990.

24 Møller S, Becker U, Schifter S, et al. Effect of oxygen inhalation on systemic, central, and splanchnic haemodynamics in cirrhosis. F Hepatol 1996;25:316-28.

25 Bendtsen F, Henriksen JH, Becker U, et al. Effect of oral propranolol on splanchnic oxygen uptake and haemodynamics in patients with cirrhosis. F Hepatol 1987;5:137-43.

26 Krowka MJ, Grambsch PM, Edell ES, et al. Primary biliary cirrhosis: relation between hepatic function and pulmonary function in patients who never smoked. Hepatology 1991;13:1095-100.

27 Rakela J, Krowka MJ. Cardiovascular and pulmonary complications of liver disease. In: Zakim D, Boyer TD, eds. Hepatology. A textbook of liver disease. Philadelphia: Saunders, 1996:675-84.

28 Bendtsen F, Henriksen JH, Widding A, et al. Hepatic venous oxygen content in alcoholic cirrhosis and non-cirrhotic alcoholic liver disease. Liver 1987;7:176-81.

29 Vachiery F, Moreau R, Hadengue A, et al. Hypoxemia in patients with cirrhosis: relationship with liver failure and hemodynamic alterations. f Hepatol 1997;27:492-5

30 Agusti AGN, Roca J, Rodriguez-Roisin R. Mechanisms of gas exchange impairment in patients with liver cirrhosis. Clin Chest Med 1996;17:49-66.

31 Chao Y, Wang SS, Lee SD, et al. Effect of large-volume paracentesis on pulmonary function in patients with cirrhosis and tense ascites. F Hepatol 1994;20:101-5.

32 Chang SC, Chang HI, Chen FJ, et al. Effects of ascites and body position on gas exchange in patients with cirrhosis. Life Sci 1995;19:143-50.

33 Oster JR, Perez GO. Derangements of acid-base homeostasis in liver disease. In: Epstein M, ed. The kidney in liver disease. Philadelphia: Hanley and Belfus, 1996:109-22.

34 Cotes JE. Lung function. Assessment and application in medicine. Oxford: Blackwell Science, 1993.

35 Lustik SJ, Chhibber AK, Kolano JW, et al. The hyperventilation of cirrhosis: progesterone and estradiol effects. Hepatology 1997;25:55-8.

36 Duranti R, Laffi G, Misuri G, et al. Respiratory mechanics in patients with tense cirrhotic ascites. Eur Resp F 1997;10: 1622-30. 